\title{
AS LARANJAS E A PANDEMIA: A POÉTICA DA MISTURA NAS AQUARELAS DE MARIA ESMÊNIA
}

\author{
The oranges and the pandemic: the poetic of mixing in the watercolors of Maria \\ Esmênia
}

\author{
Ana Maria Alves de Souza \\ https://orcid.org/0000-0002-7875-6292 \\ Secretaria Municipal de Educação, Florianópolis, SC, \\ Brasil. 88010-914 - gabinete@sme.pmf.sc.gov.br.
}

Resumo: Neste ensaio, intentamos apresentar uma reflexão acerca da poética da "mistura", (COCCIA, 2018), costurando a leitura de uma série de obras artísticas produzidas pela aquarelista Maria Esmênia, que foram postadas em sua página no Facebook durante o início da pandemia em 2020, relegando-nos ao distanciamento físico e levando-nos a uma proximidade virtual. Nosso objetivo é problematizar aqui uma leitura que pretende ser estética e política ao mesmo tempo, ao abordar as formas e cores da passagem do tempo pandêmico na vida e na obra dessa artista. Vemos na série de pinturas/colagens/fotomontagens de laranjas realizadas por Maria Esmênia, e nas cores que se transformam (CRUZ, 2001), um detalhe (RANCIÈRE, 2009), um biografema (BARTHES, 2003), um instante-já (LISPECTOR, 1973), que contam a história. Assim procedendo, procuramos fazer uma leitura de um fragmento de obra de uma artista com sua singularidade, mas também remetendo-nos a um coletivo, aos elos dessa poética com um comportamento social comum a outros artistas, cada um em seu momento de vida e singularidade, todos compartilhando em seus corpos as marcas do processo do tempo (GOLDEMBERG, 2013) que passa, misturandose com a prática artística na vida cotidiana da cidade, num movimento estético urbano espalhado pelo mundo.

Palavras-chave: Mistura; Aquarela; Cor; Detalhe; Maria Esmênia.

\begin{abstract}
We would like to discuss in this essay the poetics of the "mixing", (COCCIA, 2018) sewing the reading of a series of artistic works made by the aquarellist Maria Esmênia, posted on her Facebook page during the pandemic that affected us in 2020, relegating us to physical distance, but virtual proximity. We want to problematize a reading that intends to be both political and aesthetic at the same time, when approaching the shapes and colors of the passing of the pandemic time in the life and work of the artist. We can see in the series of paintings/collages/photo montages of oranges made by Maria Esmênia, and in the colors that transform it selves (CRUZ, 2001), a detail (RANCIĖRE, 2009), a bio grapheme (BARTHES, 2003), a brief instant (LISPECTOR, 1973) that tells the story. Thus, we proceed trying to do the reading of a fragment of work of an artist that with her singularity, but also referring to a collective, to the poetics bonds with a social behavior common to other artists, each one in their moment of life and uniqueness, all sharing in their bodies marks of the process of time (GOLDEMBERG, 2013), that passes, mixing with the artistic practice in the city's daily life, in an urban aesthetic movement spread around the world.
\end{abstract}

Keywords: Mixing; Watercolor; Color; Detail; Maria Esmênia.

\section{Introdução}

A prática cotidiana da aquarela, em Florianópolis, move uma parcela da população 
que se reunia em grupos, antes do início desta pandemia, em exercício dessa arte. Ocupando os dias de um segmento de pessoas que já passaram da meia idade, essa prática artística desdobrou-se durante a pandemia, em lives acompanhadas por diversos artistas de diferentes idades, que refizeram virtual e criativamente o circuito artístico cultural da cidade, alargando suas fronteiras e levando em frente o projeto de vida dessa população junto à arte.

Dessa forma, pude virtualmente acompanhar as postagens da aquarelista Maria Esmênia (GONÇALVES, Facebook) em sua página no Facebook, durante o início da pandemia. Destacarei aqui a série de aquarelas de laranjas produzidas (Figura 1), e sua mudança de tonalidades na paleta da artista, que pontuaram minha leitura como a um punctum (BARTHES,1984) que marca o olhar, provocando a transformação do sujeito e a reelaboração da vida através da arte.

Figura 1 - Maria Esmênia. Geleia de laranja - da série Casa Percy - laranjas.

Pôster sobre papel cartão, aquarela e colagem, 2020, $32 \times 45 \mathrm{~cm}$. Obra e foto de Maria Esmênia. Florianópolis. Post 16 out. 2020

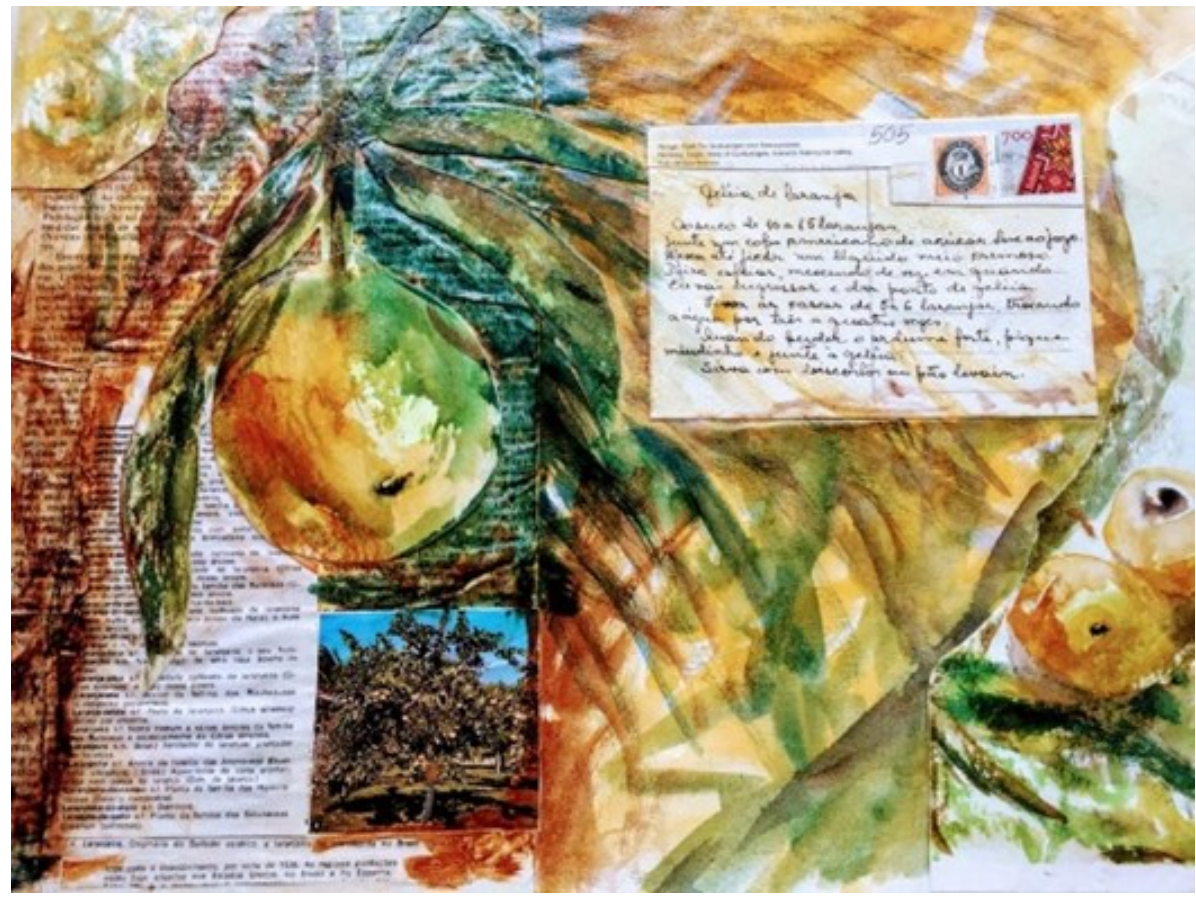

Fonte: Disponível em:

https://www.facebook.com/mariaesmenia.arte/photos/pcb.263539082114821/263538745448188/. Acesso em: 29 maio 2021.

Antes desta pandemia, Maria Esmênia frequentava o Ateliê Alvéolo, localizado nos arredores da Universidade Federal de Santa Catarina (UFSC), onde aquarelistas reuniamse sob a coordenação da artista Zulma Borges para a prática conjunta da aquarela. O grupo resiste à Pandemia mantendo o contato e, mesmo à distância, compartilham seus trabalhos artísticos virtualmente, de forma que possam ser apreciados e criticados por cada um, num esforço e estímulo poético-educativo em que cada um que pinta vê e reconhece no Outro o processo de amadurecimento dos sentidos e da técnica. Foi ali, nesses tempos passados compartilhando a prática artística da pintura em aquarela, que conheci a artista, antiga 
aluna da coordenadora do Ateliê.

Muitos do grupo que ali praticavam a aquarela em conjunto costumavam pintar a observação da natureza e a arquitetura urbana, fazendo parte de um movimento estético mundial contemporâneo chamado de Urban Sketchers (USK). Acostumados à pintura em plein air, esses artistas ficaram restritos ao ambiente doméstico como forma de inspirar a observação do espaço cotidiano. O organizador do movimento na cidade de Florianóolis, Ivan Jerônimo (2020), chegou a publicar um livro durante a pandemia por Covid-19, intitulado 60 dias dentro de casa: um diário ilustrado do isolamento, retratando em desenhos os primeiros dias do cotidiano de seu confinamento. Maria Esmênia, participante também desse movimento estético, procurou a natureza nos limites do muro da sua casa para tema de estudo, pesquisa e expressão, fazendo a série de laranjas por meio das manchas em aquarela.

Ao falarem sobre As artistas contemporâneas na teoria e na história da arte, Cherem e Makowiecky (2016) ressaltam a importância de novos esforços num mapeamento de artistas e sua produção em Santa Catarina a partir da segunda metade do século XX, em que se deve procurar relacionar tanto as persistências quanto as principais inquietações plásticas presentes no Estado. O objetivo a se ter em mente seria "reconhecer as principais questões plásticas (poéticas e faturas) e afinidades temáticas, condições de trabalho, expectativas e sociabilidades artísticas que emergem nesse circuito" (CHEREM; MAKOWIECKY, 2016, p. 253).

Dessa forma, procuramos aqui tecer considerações iniciais sobre a série de frutas pintadas por Maria Esmênia, apontando para uma poética da mistura, em que o tom rompido (CRUZ, 2001) remete-nos ao tempo que passa e aos modos de vida e de grafar o humano na memória da vida em meio à arte em tempos de pandemia.

\section{A poética da mistura}

A série de aquarelas de Maria Esmênia, que pode ser lida como uma mistura de pintura, colagens, fotomontagens, escritas com frutas, como as laranjas realizadas durante esta pandemia, une-se às outras séries de aquarelas realizadas anteriormente, de bananas, ou de araucárias com receitas culinárias, utilizando o pinhão, seu fruto. A receita do "Entrevero", nome dado ao prato eleito para destaque na aquarela, marca o costume alimentar da procedência da artista, a cidade de Lages, na serra catarinense (Figura 2). 
Figura 2 - Maria Esmênia.

Araucária e Entrevero - da série Araucárias, em papel Hahnemuhle Aniversary, $425 \mathrm{~g} / \mathrm{m} 2,24 \times 32 \mathrm{~cm}$. Aquarela e foto de Maria Esmênia. Pandemia, julho 2020. Florianópolis. Post 29 maio 2021.

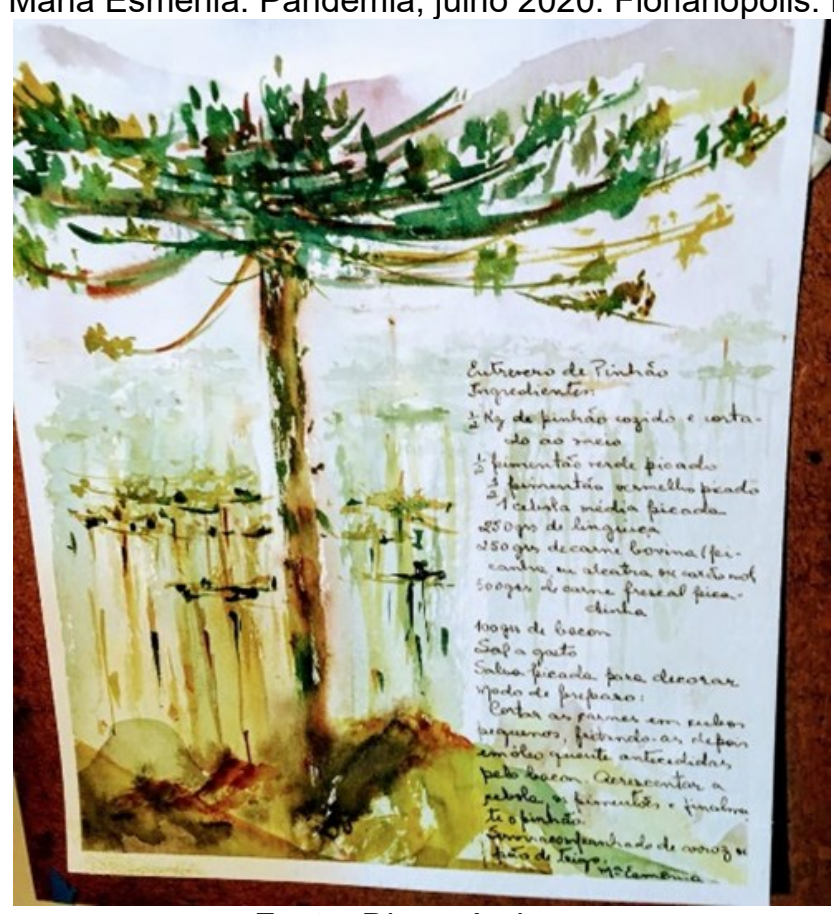

Fonte: Disponível em:

https://www.facebook.com/mariaesmenia.arte/photos/a.248573766944686/406410747827653/. Acesso em: 29 maio 2021.

As laranjas pintadas na pandemia são observadas no pátio da casa onde a artista reside há muitos anos, em Florianópolis, nas proximidades da UFSC, lugar onde trabalhou e se aposentou como professora do Centro de Educação. Por significativos serviços prestados à educação, em 2004, Maria Esmênia foi agraciada com a Medalha Antonieta de Barros, num reconhecimento público do seu trabalho. Desde sua aposentadoria, Maria Esmênia dedica-se de corpo e alma à prática artística, tornando-se, no passar do tempo, membro da Associação Catarinense de Artistas Plásticos (ACAP). Privilegiando a pintura em aquarela, porém experimentando, também, outras técnicas expressivas, em sua série de laranjas pintadas, passou por um processo de modificação na paleta de cores, durante esta pandemia, evidenciando uma mistura acentuada à medida que as notícias acerca do alastramento da contaminação pela Covid-19, em território brasileiro, agravavam-se (Figura 3).

A mudança de cores na paleta de Maria Esmênia traz a expressividade do gesto, falando da passagem do tempo e do envelhecimento orgânico, numa solução poética que nos faz pensar. Ao discorrer sobre a Teoria das Cores, José Maria Dias da Cruz (2001), artista carioca residente em Florianópolis, que anteriormente deu aulas à Maria Esmênia, menciona a questão da importância de lermos a estrutura cromática de uma obra, percebendo o rompimento de um tom. Para esse teórico e artista, "caso nossa referência seja o tom rompido, a representação de seu tom original mostra-nos sua qualidade no passado, e o presente se dá no ponto de passagem entre um e outro" (CRUZ, 2001, p. 166167). 
Figura 3 - Maria Esmênia. Laranjas queimadas.

Da série Casa Percy - laranjas. Papel Hahnemuhle Cézanne $300 \mathrm{~g} / \mathrm{m} 2,24 \times 32 \mathrm{~cm}$. Aquarela e foto de Maria Esmênia, pandemia/2020 2020. Florinópolis. Post. 21 set. 2020

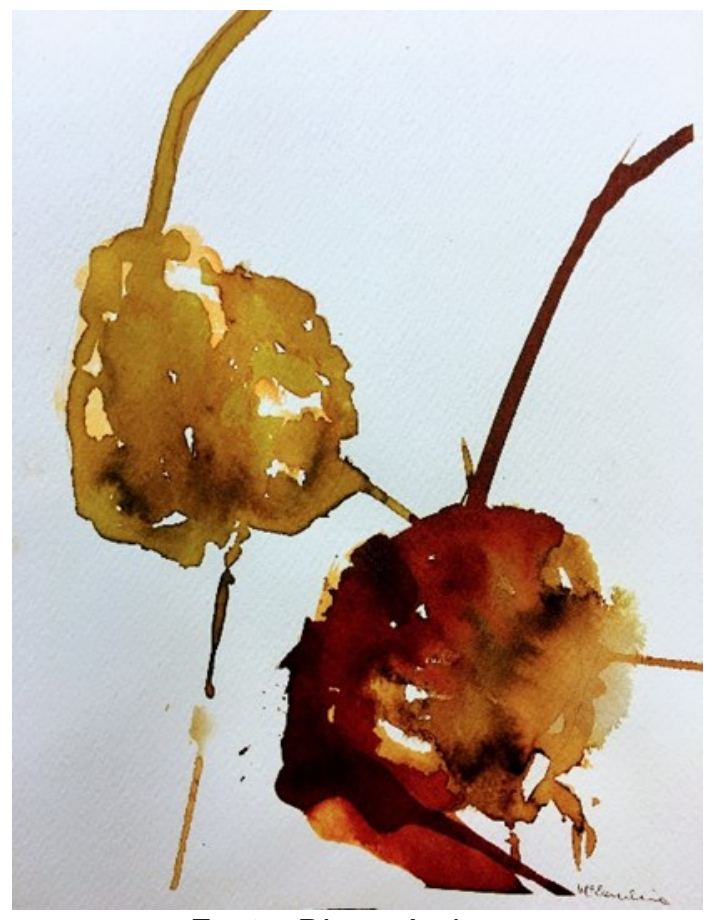

Fonte: Disponível em:

https://www.facebook.com/mariaesmenia.arte/photos/pcb.255043296297733/255043222964407/. Acesso em: 29 maio 2021.

É nessa poética da mistura que faço aqui uma leitura pessoal das cores que se transformam nessa série criada por Maria Esmênia, em que o autobiográfico daquele que narra a história mistura-se com o biográfico daquilo que se lê, como as cores mesclam-se entre si, compondo as formas. Nesse esforço, consideramos relevantes as palavras de Ricardo Piglia (2004), em seu livro Formas Breves: "o mais importante nunca se conta. A história é construída com o não-dito, com o subentendido e a alusão" (2004, p. 91-92).

Dessa forma, misturo sentidos, observando a paleta de cores das laranjas aquareladas e pensando também em A Vida das plantas, no qual Coccia (2018, p. 12-13) afirma que "o mundo é mistura" e que "estar-no-mundo já não é se achar num espaço infinito que contém toda outra coisa, mas não poder mais fazer a experiência de estar num lugar sem reencontrar esse lugar em si mesmo, e se tornar, portanto, o lugar do nosso lugar". Para Coccia (2018), a poética da mistura está contida no próprio movimento do ar que respiramos, em que conhecer o mundo é respirá-lo, e respirar significa saborear o mundo.

Ao pintar frutas e escrever suas receitas, Maria Esmênia toca a história da arte, fazendo uma versão daquilo que também pode ser chamado de "natureza-morta". Lembrome aqui de que Frida Kahlo pintou muitos conjuntos de frutas e também grafava anotações, seguidamente, em seus trabalhos artísticos. Palavra e pintura misturam-se, formando nossa própria história humana (Figura 4). 
Figura 4 - Frida Kahlo. 1954. Viva la Vida.

Óleo sobre fibra dura 59,5 x 50,8 cm. Museo Frida Kahlo, Coyoacán, México

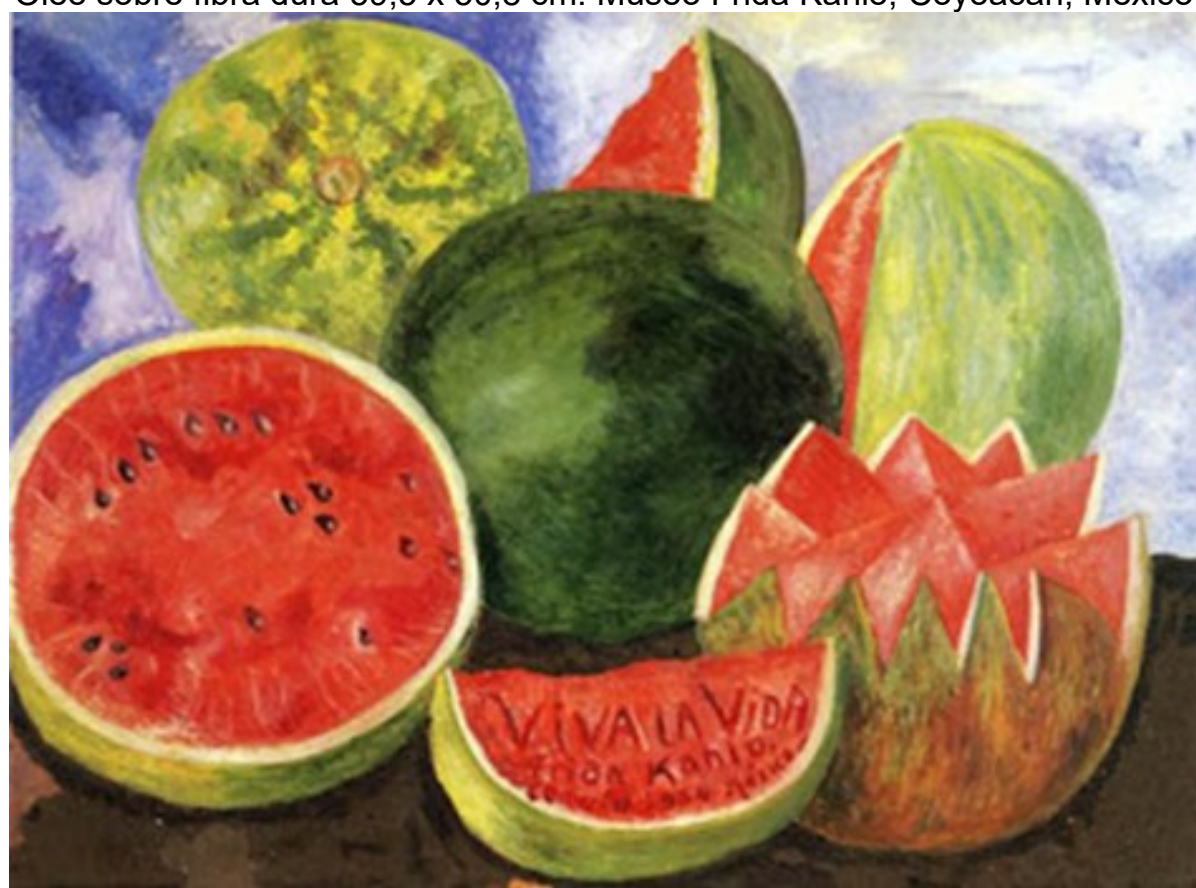

Fonte: Disponível em: http://viviendoenelmexicomagico.blogspot.com/2017/12/viva-la-vida-suposta-ultimatela-de.html. Acesso em: 29 maio 2021.

"Viva la Vida" é a grafia do detalhe que Frida Kahlo incrusta no vermelho da melancia. Rancière (2009), no livro O inconsciente estético, fala da importância do detalhe para a revolução estética. Segundo este autor,

A regra freudiana de que não existem detalhes desprezíveis, de que, ao contrário, são esses detalhes que nos colocam no caminho da verdade, se inscreve na continuidade direta da revolução estética. Não existem temas nobres e temas vulgares, muito menos episódios narrativos importantes e episódios descritivos acessórios. Não existe episódio, descrição ou frase que não carregue em si a potência da obra. Porque não há coisa alguma que não carregue em si a potência da linguagem. Tudo está em pé de igualdade, tudo é igualmente importante, igualmente significativo. (RANCIÈRE, 2009, p. 36-37).

Trilhando os caminhos da leitura do detalhe, Souza (2011) pensa a questão (auto)biográfica através da ideia de "biografema", retirada de Barthes (2003), que nunca propriamente definiu este conceito, mas o espalhou, em vários momentos, por sua obra. Poderíamos dizer que, para esse autor, o "biografema" é o detalhe que conta do biografado, a vida, atingindo o olhar daquele que lê como aquilo de marcante e significativo que constrói a imagem do Outro. Ao fazer sua leitura de diferentes biografias sobre Frida Kahlo através do sensível, Souza destaca a crítica da biógrafa Patrícia Mayayo (2008) às outras tantas biógrafas da artista.

[...] à relação simplista entre vida e obra, sem negar a natureza autobiográfica da pintura de Frida, [Mayayo] almeja transcender a leitura psicobiográfica por acreditar que estudar Frida em termos exclusivamente biográficos reforçará o confinamento das mulheres artistas no âmbito do 
privado e ajudará a consolidar grande parte dos estereótipos sobre a criatividade feminina difundidos no século XIX. (SOUZA, 2011, p. 64) .

Essa biografa de Frida aponta para a importância de uma leitura política da obra da artista, em que estética e política misturam-se dando um outro sentido às obras. Dessa forma, fazendo uma leitura do presente, por ironia do destino ou desígnio dos governantes, a verdade é que em 2020 ficamos confinadas/os, nesta pandemia, no cuidado preventivo da contaminação, prerrogativa esta que coagiu especialmente a população idosa ao distanciamento social, ou mesmo, às intempéries de um isolamento necessário, na procura dos cuidados de si e do Outro. Maria Esmênia, no entanto, não se deixa arrefecer pelos limites impostos, com o tempo que passa e a idade que avança; como mulher ativa que sempre foi, constrói seu cotidiano pandêmico intensificando ainda mais sua produção, fazendo da arte o seu estar no mundo, que vê poesia no restrito espaço onde se encontra, e, através das cores, respira, nesse misturar-se que Coccia (2018) diz ser próprio do vivente.

Por outro lado, num tempo recente, Paulo Gaiad (2005) compôs suas "Memórias de Cozinha" numa mistura de fotoimagens que remetem à passagem do tempo e ao cotidiano, que traz a natureza-morta. Composta por pequenas imagens $20 \times 20 \mathrm{~cm}$, o painel "Memórias de Cozinha" traz ovos, copo de água e bananas sobre uma mesa, misturadas com fotografias antigas de pessoas, que o artista ali combinou, formando foto-collages.

Figura 5 - Paulo Gaiad. Série "Memórias de Cozinha".

Fotografia sobre papel filtro, painel (parcial) com 16 peças, $20 \times 20 \mathrm{~cm}$ cada uma. 2005.
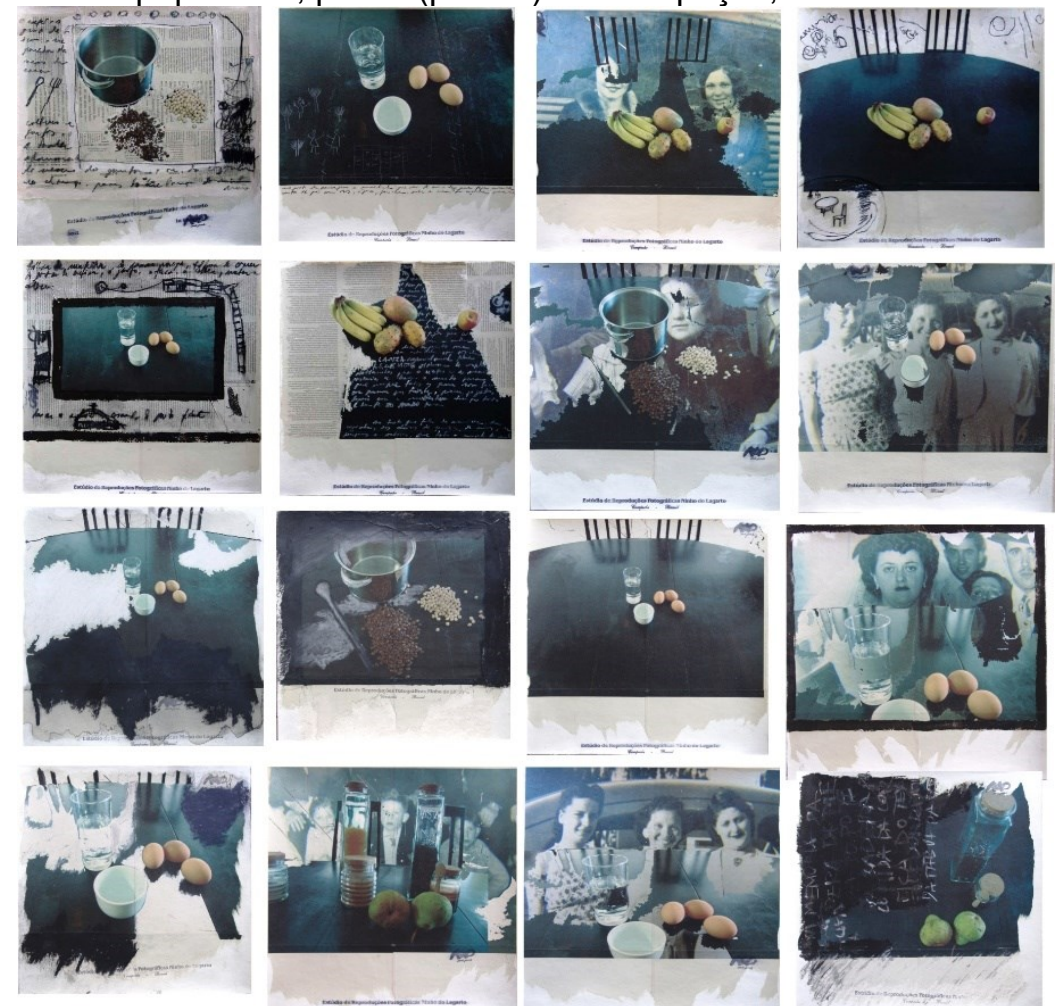

Fonte: Imagem de Arquivo pessoal do artista - ACERVO ARTÍSTICO PAULO GAIAD (www.paulogaiad.com) 
Ana Maria Guasch (2005) fala que a fotomontagem e a collage eram procedimentos comuns nas vanguardas artísticas do início do século $\mathrm{XX}$, procedimentos similares à contemporânea forma de arquivo como organização sistemática do conhecimento. É interessante observar, numa das aquarelas de Maria Esmênia, o detalhe da colagem de um cartão-postal em que, em seu verso evidente, está escrita uma receita de geleia de laranja (Figura 1), misturando a grafia e as cores dos pigmentos diluídos. Para pensarmos essas leituras, lembro que Chimamanda Ngozi Adiche (2019) já nos aponta sobre os perigos de uma história única, e da importância de ouvirmos uma multiplicidade de versões desta, pois são essas narrativas que constroem a imagem que formamos do Outro.

$\mathrm{Na}$ intensidade desse processo pandêmico iniciado em março de 2020, a série de laranjas de Maria Esmênia nos trazem a possibilidade de refletir sobre essa mistura espaçotemporal, tanto do "instante-já" que Clarice Lispector (1973) evidencia em Água Viva, ao misturar a palavra e a pintura, quanto do poema "Domingo", de Adelia Prado ([197-?]), que Maria Esmênia grafa em outra aquarela, trazendo-nos a marca da arte que, no processo do tempo aquarelado, traz a leitura da memória do eterno e do que passa (Figura 5).

Figura 5 - Maria Esmênia.

Domingo, laranjas e bicicletas II, da série Casa Percy - laranjas, papel Hahnemuhle Cézane, $300 \mathrm{~g} / \mathrm{m} 2,30 \mathrm{x}$ 40 cm. Quarentena de 2020. Poesia "Domingo", de Adélia Prado. Post 24 out. 2020

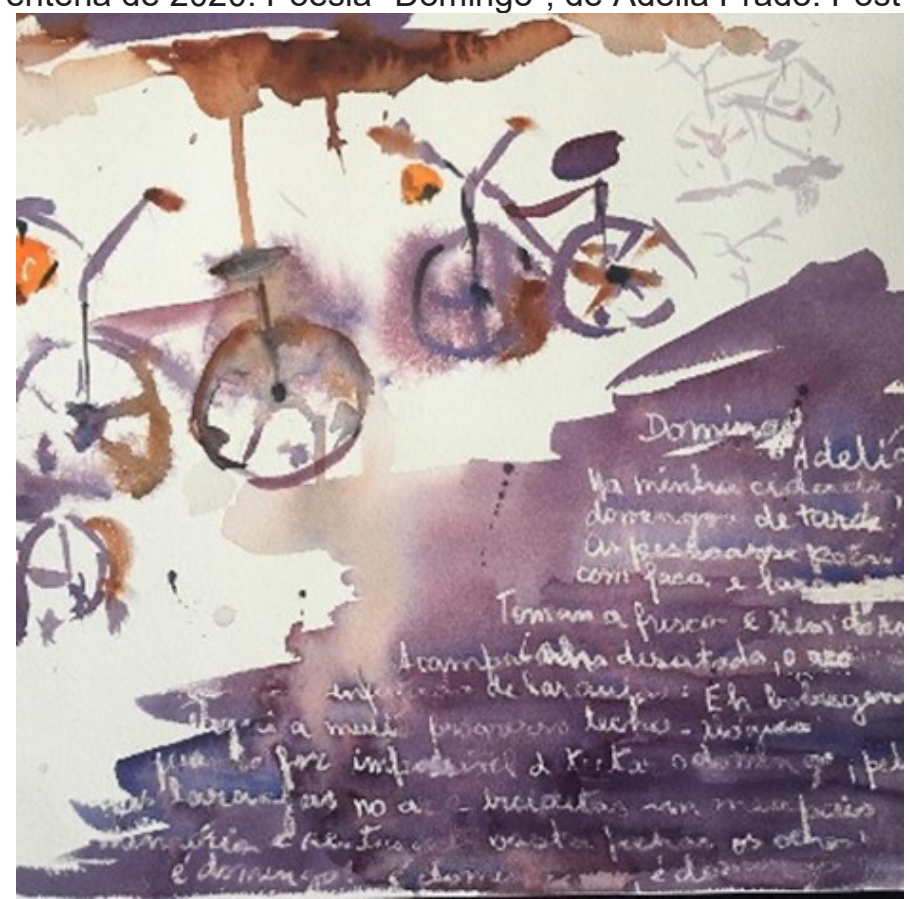

Fonte: Disponível em:

https://www.facebook.com/mariaesmenia.arte/photos/pcb.266180515184011/266180398517356/. Acesso em: 28 maio 2021.

A pesquisadora Maira Carmo Marques (2012), em sua dissertação de mestrado em Letras, apresentada na Universidade de São Paulo (USP), sobre a poesia de Adélia Prado, afirma que "desfazer tensões, aliar contrários é o procedimento central de sua poesia" (MARQUES, 2012, p.112). Ao sintetizar sua argumentação, Marques (2012) menciona que

A poesia de Adélia Prado é certamente um incômodo na poesia brasileira, 
poesia que, justamente no contexto da ditadura militar, tende a enfatizar, ou mesmo defender valores tradicionais tais como a família e a religiosidade católica. Ecoa em seus versos o tradicional discurso conservador brasileiro, revitalizado pela ditadura militar, ao mesmo tempo em que sua poesia lhe escapa. Seus poemas, através de um romantismo crítico, repensam o cotidiano dando-lhe novos significados, a partir da perspectiva dos mais simples. (MARQUES, 2012, p. 7).

Essa pesquisadora aponta para algumas questões que me remeteram à leitura da poética da mistura, como aqui já mencionado. No poema "Domingo", Adelia Prado ([197?]) mistura o tempo da memória que se repete no calendário, como um eterno retorno, às laranjas e à bicicleta de um tempo que passou.

As laranjas pintadas por Maria Esmênia denotam um instante que se intensifica no gesto plástico. Poderíamos aqui nos remeter, também, a Clarice Lispector (1973), em Água Viva, em que ela escreve, mesclando a arte da palavra com a arte das tintas, numa ficção que tem como tema o instante. Diz essa escritora/artista que "[...] cada coisa tem um instante em que ela é. Quero apossar-me do é da coisa" (LISPECTOR, 1973, p. 10). Em dezembro de 2020, é comemorado o centenário de nascimento de Clarice, mês no qual tecemos estas considerações sobre a poética da artista catarinense Maria Esmênia.

\section{Considerações finais}

Com a aquarela, a artista mancha o papel como o tempo mancha com diversas tonalidades a pele, deixando a marca de sua passagem. Como diz Clarice (1973), ao tentar escrever "com o corpo todo":

Não pinto ideias, pinto o mais inatingível 'para sempre'. Ou 'para nunca', é o mesmo. Antes de mais nada, pinto pintura. $E$ antes de mais nada te escrevo dura escritura. Quero como poder pegar com a mão a palavra. A palavra é objeto? E aos instantes eu lhes tiro o sumo da fruta. Tenho que me destituir para alcançar cerne e semente de vida. O instante é semente viva. (LISPECTOR, 1973, p. 13).

Neste passar contínuo de instantes pandêmicos, remetemo-nos à pesquisa feita anteriormente por Míriam Goldemberg (2013) com homens e mulheres no Rio de Janeiro sobre representações do processo de envelhecimento. Essa antropóloga entrevistou cinquenta pessoas, analisando suas respostas em busca de compreender quais os aspectos positivos ou negativos do envelhecimento. Ao falar em seu livro sobre a "bela velhice", Goldemberg (2013) remete à Simone de Beauvoir que dizia da importância de se ter um projeto de vida para a construção dessa espécie de retrato positivo do envelhecimento. Para Goldemberg,

[...] a 'bela velhice' é o resultado natural de 'um belo projeto de vida', que pode ser construído desde muito cedo, ou mesmo tardiamente, por cada um de nós. A beleza da velhice está, exatamente, na sua singularidade, nas pequenas e grandes escolhas que cada indivíduo faz ao buscar concretizar o seu projeto de vida. (GOLDEMBERG, 2013, n.p). 
Maria Esmênia tem seu projeto de vida voltado à prática artística no cotidiano. Não é nossa intenção esgotar aqui a leitura possível que a obra dessa artista se nos apresenta, mas grafá-la no fragmento da poética da mistura contida nas tonalidades que formam suas laranjas, nesse instante singular no qual nos encontramos, a pandemia do Covid-19, evidenciando o tempo que passa. As aquarelas de Maria Esmênia diluem seu pigmento de preocupações na água viva da pintura, misturando, no papel e na pele da vida, manchas, escritas e formas, num compartilhar, com seus pares, um processo de vida.

\section{Referências}

ADICHIE, Chimamanda. Ngozie. O perigo de uma história única. São Paulo: Companhia das Letras, 2019.

BARTHES, Roland. A câmara clara. Rio de Janeiro: Nova Fronteira, 1984.

BARTHES, Roland. Roland Barthes por Roland Barthes. São Paulo: Estação Liberdade, 2003.

CHEREM, Rosangela; MAKOWIECKY, Sandra (org.). Artistas contemporâneas na Teoria e História da Arte. Florianópolis: AAESC, 2016.

COCCIA, Emanuele. A vida das plantas: uma metafísica da mistura. Desterro [Florianópolis]: Cultura e Barbárie, 2018.

CRUZ, José Maria Dias da. A Cor e o Cinza: rompimentos, revelações e passagens. Rio de Janeiro: Taba Cultural, 2001.

GOLDEMBERG, Míriam. A Bela Velhice. Rio de Janeiro: Record, 2013. E-book.

GONÇALVES, Maria Esmênia Ribeiro. Maria Esmênia. Florianópolis, 29 jul. 2020. Facebook. Página da administradora. Disponível em: https://www.facebook.com/mariaesmenia.arte. Acesso em: 20 maio 2021.

GUASCH, Ana Maria. Los lugares de la memoria: el arte de archivar y recordar. Materia. Revista del Departamento de Historia del Arte, Barcelona, v. 5, p. 157-183, 2005. Diaponível em: https://colectivoam.files.wordpress.com/2012/05/el-arte-de-archivar-y-recordar.pdf. Acesso em: 20 maio 2021.

JERÔNIMO, Ivan. 60 dias dentro de casa: um diário ilustrado do isolamento. Florianópolis: Edição do Autor, 2020. Disponível em: http://www.ivanjeronimo.com.br/essays/. Acesso em: 29 nov. 2020.

LISPECTOR, Clarice. Água Viva. Rio de Janeiro: Editora Arte Nova S.A., 1973.

MARQUES, Maira Carmo. A poesia de Bagagem, de Adelia Prado. 2012, 121 p. Dissertação (Mestrado em Teoria Literária e Literatura Comparada) - Faculdade de Filosofia, Letras e Ciências Humanas, Universidade de São Paulo, São Paulo, 2012. Disponível em: https://www.teses.usp.br/teses/disponiveis/8/8151/tde-09112012093125/publico/2012_MairaCarmoMarquez.pdf. Acesso em: 21 maio 2021. 
PIGLIA, Ricardo. Formas breves. São Paulo: Companhia das Letras, 2004.

RANCIĖRE, Jacques. O inconsciente estético. São Paulo: Ed. 34, 2009.

SOUZA, Ana Maria Alvez. Frida Kahlo: Imagens (auto) biográficas. 2011, 145 p. Dissertação (Mestrado em Literatura) - Centro de Comunicação e Expressão, Universidade Federal de Santa Catarina, Florianópolis, 2011. Disponível em: http://www.pmf.sc.gov.br/arquivos/arquivos/pdf/20_10_2014_19.57.41.6f73d4c598f1cfc41 77cf78081402296.pdf. Acesso em: 29 nov. 2020.

\section{NOTAS DE AUTORIA}

Ana Maria Alves de Souza (ana.ilinix@gmail.com) é formada na Licenciatura em Artes Plásticas (1999, CEART/UDESC), com mestrados em Antropologia Social (2003, UFSC) e também em Literatura (2011, UFSC). É professora de Artes Visuais da Rede Municipal de Florianópolis com 10 anos de atuação, sendo efetiva na EBM João Alfredo Rohr (Córrego Grande).

\section{Agradecimentos}

Não se aplica.

\section{Como citar esse artigo de acordo com as normas da ABNT}

SOUZA, Ana Maria Alves de. As laranjas e a pandemia: a poética da mistura nas aquarelas de Maria Esmenia. Anuário de Literatura, Florianópolis, v. 26, p. 01-11, 2021.

\section{Contribuição de autoria}

Não se aplica.

\section{Financiamento}

Não se aplica.

\section{Consentimento de uso de imagem}

As imagens utilizadas foram cedidas pela artista protagonista do texto, Maria Esmênia, imagens que também podem ser vistas em sua página no Facebook: https://www.facebook.com/mariaesmenia.arte.

\section{Aprovação de comitê de ética em pesquisa}

Não se aplica.

\section{Conflito de interesses}

Não se aplica.

\section{Licença de uso}

Os/as autores/as cedem à Revista Anuário de Literatura os direitos exclusivos de primeira publicação, com o trabalho simultaneamente licenciado sob a Licenca Creative Commons Attribution (CC BY) 4.0 International. Estra licença permite que terceiros remixem, adaptem e criem a partir do trabalho publicado, atribuindo 0 devido crédito de autoria e publicação inicial neste periódico. Os autores têm autorização para assumir contratos adicionais separadamente, para distribuição não exclusiva da versão do trabalho publicada neste periódico (ex.: publicar em repositório institucional, em site pessoal, publicar uma tradução, ou como capítulo de livro), com reconhecimento de autoria e publicação inicial neste periódico.

\section{Publisher - uso exclusivo da revista}

Universidade Federal de Santa Catarina. Programa de Pós-graduação em Literatura. Publicação no Portal de Periódicos UFSC. As ideias expressadas neste artigo são de responsabilidade de seus/suas autores/as, não representando, necessariamente, a opinião dos/as editores/as ou da universidade.

\section{Histórico}

Recebido em: 04/12/2020

Aprovado em: 17/03/2021

Publicado em: 08/12/2021 